Sādhanā Vol. 38, Part 6, December 2013, pp. 1067-1082. (C) Indian Academy of Sciences

\title{
Boiling flow through diverging microchannel
}

\author{
V S DURYODHAN ${ }^{\mathrm{a}}$, S G SINGH ${ }^{\mathrm{b}}$ and AMIT AGRAWAL ${ }^{\mathrm{a}, *}$ \\ ${ }^{a}$ Department of Mechanical Engineering, Indian Institute of Technology Bombay, \\ Powai, Mumbai 400 076, India \\ ${ }^{\mathrm{b}}$ Department of Electrical Engineering, Indian Institute of Technology, \\ Hyderabad 502 205, India \\ e-mail: amit.agrawal@iitb.ac.in; amit.agrawal@me.iitb.ac.in
}

MS received 9 February 2012; revised 3 January 2013; accepted 31 January 2013

\begin{abstract}
An experimental study of flow boiling through diverging microchannel has been carried out in this work, with the aim of understanding boiling in nonuniform cross-section microchannel. Diverging microchannel of $4^{\circ}$ of divergence angle and $146 \mu \mathrm{m}$ hydraulic diameter (calculated at mid-length) has been employed for the present study with deionised water as working fluid. Effect of mass flux (118$\left.1182 \mathrm{~kg} / \mathrm{m}^{2}-\mathrm{s}\right)$ and heat flux $\left(1.6-19.2 \mathrm{~W} / \mathrm{cm}^{2}\right)$ on single and two-phase pressure drop and average heat transfer coefficient has been studied. Concurrently, flow visualization is carried out to document the various flow regimes and to correlate the pressure drop and average heat transfer coefficient to the underlying flow regime. Four flow regimes have been identified from the measurements: bubbly, slug, slug-annular and periodic dry-out/ rewetting. Variation of pressure drop with heat flux shows one maxima which corresponds to transition from bubbly to slug flow. It is shown that significantly large heat transfer coefficient (up to $107 \mathrm{~kW} / \mathrm{m}^{2}-\mathrm{K}$ ) can be attained for such systems, for small pressure drop penalty and with good flow stability.
\end{abstract}

Keywords. Diverging microchannel; two-phase flow; pressure drop; flow regimes; flow instability.

\section{Introduction}

Miniaturization of microelectronic devices, like Very Large Scale Integration (VLSI) and MetalOxide-Semiconductor Field-Effect Transistor (MOSFET) based systems, are pushing the heat flux density requirements to higher levels. Singh et al (2009a, 2011) performed in situ impact analysis of very high heat flux transients on the characteristics of resistance-temperature detector (RTD), $\mathrm{p}-\mathrm{n}$ diode and MOSFET. The authors showed that the performance of $\mathrm{p}-\mathrm{n}$ diode gets affected by high transient heat flux conditions $\left(153 \mathrm{~W} / \mathrm{cm}^{2}\right)$, which can be successfully mitigated by employing microchannel, based cooling. Liquid-based cooling for electronic systems can remove high density heat flux; further heat removal can be attained by employing two-phase

*For correspondence 
flow. Singh et al (2011) reported that the rate of mitigation of heat in MOSFET operation is higher at lower flow rates because of the higher heat transfer efficiency of two-phase flow. They also proposed a technique for localizing hotspots by utilizing an on-chip distributed RTD sensor array. These and other advances have allowed dissipation of about $200 \mathrm{~W} / \mathrm{cm}^{2}$ of heat. The new challenge for the coming decade is mitigating heat flux in the order of $600-1000 \mathrm{~W} / \mathrm{cm}^{2}$ (Mudawar 2001). Such high level of heat dissipation requires a dramatic reduction in the cooling channel dimensions so that a higher surface area to volume ratio can be achieved. However, work carried out by different research groups on two-phase boiling flow through microchannels suggest several difficulties in successful implementation of two-phase boiling flow in practical applications. The challenges include high pressure drop, flow instability and intermittent dry-out; which leads to a reduction in critical heat flux (CHF) resulting in possible burn out of the device. Therefore, for successful implementation of two-phase boiling flow in microscale systems like microchannel-based heat sink requires systematic study based on experimental data.

Numerous research works have been carried out by different researchers to understand the critical phenomena that are encountered during flow boiling in microchannel. Kennedy et al (2000) experimentally studied the onset of nucleate boiling (ONB) and onset of flow instability (OFI) in uniformly heated microchannels of inner diameter $1.45 \mathrm{~mm}$ with subcooled water flow. They generated demand curves (pressure drop versus flow rate curve) and utilized these for specification of the ONB and OFI points. They observed that the instability sets in at a slightly lower mass flux than the onset of significant void condition. Kandlikar (2002) studied flow boiling of water in electrically heated multichannel evaporators consisting of six parallel microchannels. They used a 1000 frames per second camera to visualize the ensuing flow patterns (bubbly, slug, and annular). Further, nucleation was observed in the bulk fluid as well as in the liquid film. The visual confirmation of flow reversal in some of the microchannels was also obtained from their experiments. Singh et al (2009b) also reported different flow regimes (bubbly, slug and annular) with boiling water in a microchannel of hydraulic diameter $140 \mu \mathrm{m}$. They developed a novel image analysis method to determine the void fraction and frequency of occurrence of different regimes, and presented a unique flow regime map. Qu \& Mudawar (2003) studied two-phase pressure drop of water flowing in 21 parallel copper microchannels heat sink, each having a cross section of $231 \times 713 \mu \mathrm{m}^{2}$. They found that two types of two-phase hydrodynamic instability occur during flow boiling - severe pressure drop oscillation and mild parallel channel instability, and speculated the possibility of reversed flow. In their subsequent work (Qu \& Mudawar 2004), they observed backflow of vapor from the microchannels into the inlet plenum as CHF was approached. Wu \& Cheng (2006) carried out simultaneous visualization and measurements to study pressure drop and flow instabilities at various mass fluxes and heat fluxes during flow boiling of deionised water in a $60 \mathrm{~mm}$ long, eight parallel microchannels, each of hydraulic diameter $72.7 \mu \mathrm{m}$ etched on silicon. They observed occurrence of ONB and OFI in their microchannels which depend on both mass flux and heat flux. With increase of heat flux, OFI moved towards the direction of larger mass flux, and at the same time, the difference in mass fluxes between ONB and OFI decreased. Kandlikar \& Balasubramanian (2005) visualized water flow through a microchannel of hydraulic diameter $333 \mu \mathrm{m}$ at different mass flux, heat flux and microchannel locations using a high speed camera. Channel dry-out and rewetting were observed periodically. They also observed reversed flow liquid-vapor interfaces in a few microchannels. Kandlikar (2006) suggested that the onset of nucleate boiling introduces a pressure spike at the nucleation location. This pressure spike can be stabilized by introducing a pressure drop element, in addition to artificial nucleation sites, and by operating the system with an inlet pressure above the pressure spike. Singh et al (2008) studied the impact of aspect ratio on flow boiling of water in different rectangular microchannels of same hydraulic diameter of $142 \mu \mathrm{m}$ and length 
of $20 \mathrm{~mm}$. They observed experimentally that the minimum pressure drop across the rectangular microchannel occurs at an aspect ratio of about 1.56. This finding is relevant to reduce the pressure penalty with flow boiling in microchannel. Furthermore, they suggested that annular flow model is good for approximately square cross-sections but poor for large aspect ratio rectangular cross-section microchannels. Lee et al (2004) and Li et al (2004) experimentally investigated bubble dynamics in a single microchannel having a hydraulic diameter of $41.3 \mu \mathrm{m}$ and two parallel microchannels with a hydraulic diameter of $47.7 \mu \mathrm{m}$, respectively using DI water as working fluid. It was observed that the reversed flow occurred more easily during flow boiling in a test section having multiple microchannels than in a single microchannel.

In summary, the work done by different researchers on flow boiling in uniform cross section microchannel suggests a great concern for flow instabilities in two-phase boiling flow. Flow instability could lead to lowering the value of $\mathrm{CHF}$, resulting in damage to the microelectronics chip and can therefore lead to serious performance issues. Bergles \& Kandlikar (2005) argued that CHF gets affected by flow oscillation. Kuo \& Peles (2008) quoted that flow instabilities in microchannels not only cause an uneven thermal stress on the heating surface, but also lead to an early appearance of CHF. Park et al (2009) in their work on effect of inlet orifice on saturated CHF shows that flow easily gets subjected to instability and CHF value decreases more in the absence of an orifice than in the presence of an orifice. Given its significance, various groups have made efforts to reduce the flow instability during boiling in microchannels. Whereas some workers tried inserting throttling devices at the inlet, others have worked with different shapes and sizes of microchannels. For example, Wang et al (2008) studied flow boiling instability with water as working fluid in parallel microchannels in presence of external flow resistors, as also suggested by Qu \& Mudawar (2003). Using different inlet and outlet configurations they found that the microchannel in which the flow enters through the restriction and exits freely exhibits much less flow instabilities. Lee \& Pan (2008) studied and compared the boiling heat transfer and two-phase flow of water in a single shallow uniform cross-section microchannel ( $\left.h=20 \mu \mathrm{m}, D_{h}=33.3 \mu \mathrm{m}\right)$ and a diverging microchannel $\left(h=20 \mu \mathrm{m}, D_{h}=33.3 \mu \mathrm{m}\right)$ with a small divergence angle of $0.183^{\circ}$. They noted that for the same mass flow rate, the diverging microchannel shows a higher single-phase flow pressure drop, while the two-phase pressure drop is approximately the same. Bhide et al (2011) studied the effect of external pulsations on flow boiling. They observed that the pressure fluctuation reduce significantly with external pulsation; also the average pressure drop was found to reduce for certain cases. They proposed that the external pulsations impact the size and departure frequency of bubbles formed at the heated surface, thereby affecting the amplitude of the pressure fluctuations. Agrawal et al (2012) studied the effect of divergence angle on mean and transient pressure/temperature distribution and explored the possibilities of reduction in boiling flow instabilities using diverging microchannel. See Agrawal \& Singh (2011) for a comprehensive and up-to-date review on flow boiling in microchannel.

In case of boiling in uniform cross section microchannel, vapor bubbles get trapped inside the microchannel at nucleation sites before full growth and departure is realized since the characteristic dimension is of the order of the bubble size. This phenomenon leads to an increase in the static pressure inside the microchannel; and may manifest as an adverse pressure gradient and result in back flow. The idea of providing the divergence angle is to allow lateral space for full growth and easy departure of the vapor bubble along the flow direction. For conventional size channel, bubbles depart after full growth as the channel size is rather large. The idea of using a diverging passage is therefore expected to be more effective at the microscales. The present work focuses on two-phase flow phenomenon occurring in diverging cross-section microchannel with the aim of reducing the flow instability. The effects of mass flux and heat flux on pressure 
drop and heat transfer coefficient have been studied experimentally in this work. Different flow regimes in diverging microchannel observed using flow visualization technique have been presented and their effect on the heat transfer coefficient has been discussed. Also, the transient variation of pressure and temperature has been discussed for the different flow regimes.

\section{Experimental set-up}

Schematic of the experimental set-up employed for the measurements is shown in figure 1, which is similar to that employed earlier by Singh et al (2008, 2009c). It consists of deionized water reservoir, peristaltic pump, damper (to remove pressure fluctuations in the incoming stream), differential pressure gauge, test section, DC power supply, data logger for inlet/outlet and surface temperature recording, and a high speed camera. All devices are connected using silicone tubing (Master Flex). A pre-calibrated peristaltic pump (Master Flex) is used for metering and controlling the mass flow rate of water. A pre-calibrated digital pressure gauge (Keller) with a sampling

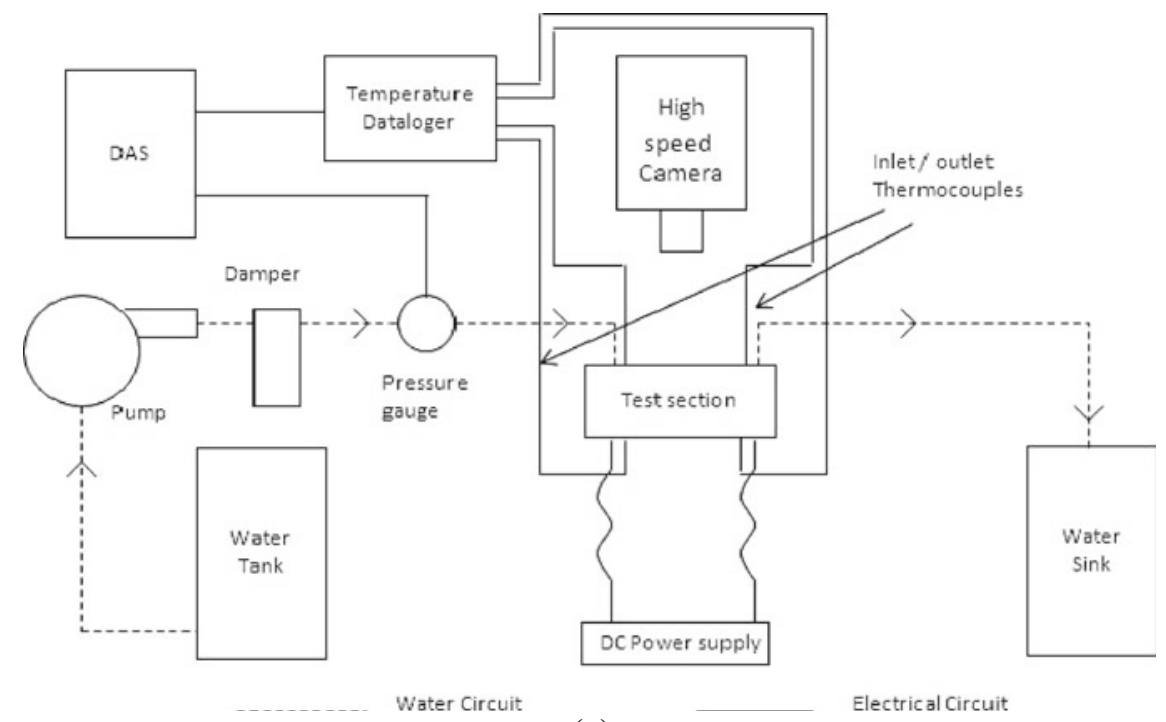

(a)

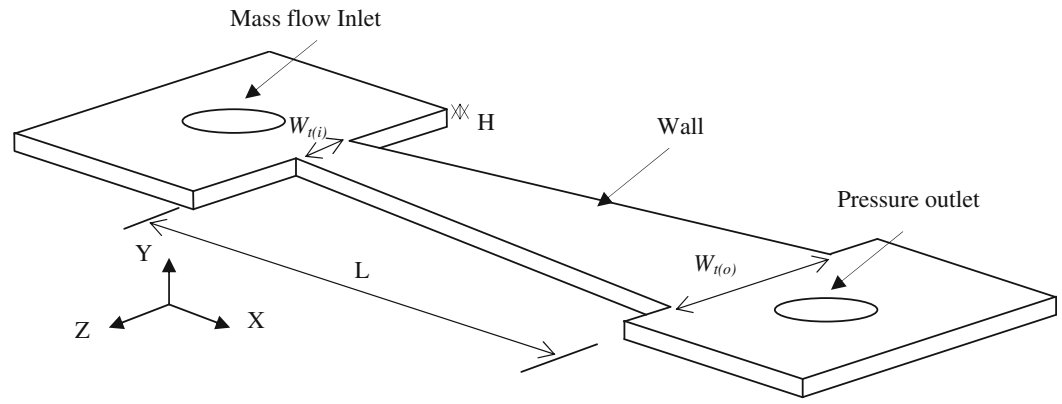

(b)

Figure 1. (a) Schematic of experimental set-up, (b) 3D view of microchannel geometry employed in the present experiments. 
rate of $1 \mathrm{~s}$ and range of -1 to 3 bars is used to measure the pressure across the microchannel. A contact probe is used to make electric contact between microheater and power source meter. Good electrical contact was ensured throughout the entire experiment. Pre-calibrated K-type thermocouples (Cole-Parmer) are placed at inlet and outlet reservoirs. Also, K-type thermocouples (ANBE SMT Co.) of bead size $25 \mu \mathrm{m}$ are placed on opposite side surface of microchannel (just below the entry/exit points). All thermocouples (four in total) are connected to a data logger to record the temperature.

The microchannel employed in this study is fabricated in-house using micro-fabrication facility. Single-sided polished, (100) p-type, $50 \mathrm{~mm}$ silicon wafer with resistivity $0.002-0.005 \Omega$ is used for fabrication. The fabrication process can be divided into RCA (named after Radio Corporation of America) cleaning, wet oxidation, photolithography, tetramethylammonium hydroxide (TMAH) etching and bonding (Singh et al 2008). Photolithography is the conventional fabrication technique used to transfer the pattern from hard mask to soft mask over an oxidized wafer. Silicone oxide acts as the soft mask for TMAH etching where precise control of the process parameters decides the surface roughness. After TMAH etching platinum micro heater is fabricated on the opposite side of the silicon wafer using metal sputter technique. Wafer bonding with quartz plate is an important step as it decides the maximum pressure that the test section can withstand without leakage. Characterization of etched microchannel is done on a profilometer, where microchannel depth and surface roughness are determined. The surface roughness of all the microchannels is less than $0.1 \mu \mathrm{m}$, as measured using a surface profilometer (Ambios XP2).

Detailed geometrical specifications of the microchannel employed in the experiments are as follows: Diverging microchannel of divergence angle $4^{\circ}$ and hydraulic diameter of $146 \mu \mathrm{m}$ is fabricated with inlet top width $\left(\mathrm{W}_{\mathrm{t}(\mathrm{i})}\right) 229 \pm 2 \mu \mathrm{m}$, outlet top width $\left(\mathrm{W}_{\mathrm{t}(\mathrm{o})}\right) 1629 \pm 2 \mu \mathrm{m}$, and height/depth of microchannel is $81 \mu \mathrm{m}$. The hydraulic diameter is calculated using the mean value of the inlet and outlet widths, i.e., at the midpoint of the microchannel. The length of section is maintained constant at $20 \mathrm{~mm}$. The dimensions of the reservoirs at the two ends are $7 \mathrm{~mm} \times 7 \mathrm{~mm}$ in size, with depth equal to the microchannel depth.

The pressure gauge reading gives the pressure drop in test section including the losses inside the connecting tubes, fittings, and entry/exit. The pressure drop across the tubing without the microchannel is also measured; this reading was validated against theory over the entire range of flow rate $(0.1$ to $1.0 \mathrm{ml} / \mathrm{min})$. The net pressure drop across the test section has been obtained by subtracting the pipe losses. Note that the silicone tubing used in the experiments did not affect the pressure instabilities reported here.

The following procedure was followed while performing the experiments. Deionized water was vigorously boiled for $30 \mathrm{~min}$ to remove dissolved air and then cooled to the ambient temperature of $25^{\circ} \mathrm{C}$. The flow was started and then an input electric power was provided by

Table 1. Estimation of error in various parameters measured.

\begin{tabular}{lc}
\hline Parameter & Maximum error \\
\hline$\dot{m}$ & $0.01 \mathrm{ml} / \mathrm{min}$ \\
$\Delta P$ & $2 \mathrm{mbar}$ \\
$T$ & $0.5^{\circ} \mathrm{C}$ \\
Electrical power supplied & $0.03 \mathrm{~W}$ \\
$D_{h}$ & $1.12 \%$ \\
\hline
\end{tabular}


supplying a fixed voltage and current using a power source meter. Continuous monitoring of the inlet, outlet and surface temperatures, and pressure drop were done to check for steady state. Once steady state condition is achieved, all relevant parameters such as pressure drop, inlet, outlet and surface temperatures, supplied power and flow rate are recorded as a function of time. The estimation of errors involved in the measurement of the various parameters is shown in Table 1. The above procedure is repeated for the entire range of flow rates and heat input.

\section{Data reduction}

This section deals with the procedure adopted for calculating the heat transfer coefficient, Nusselt number and exit thermodynamic quality. The power supplied to the micro heater is also used to heat the water inside the inlet reservoir. Therefore, water gets heated before entering the microchannel. The power utilized to heat the water inside reservoir is given as,

$$
P_{\text {reservoir }}=\dot{m} C_{p}\left(T_{i n}-T_{a m b}\right) \text {. }
$$

Therefore, input power to flow in the microchannel is

$$
P_{\text {channel }}=P_{\text {supplied }}-P_{\text {reservoir }} .
$$

The exit thermodynamic quality is calculated as

$$
x_{e}=\frac{q^{\prime} L-\dot{m} C_{p}\left(T_{s a t}-T_{i n}\right)}{h_{f g} \dot{m}},
$$

where $q^{\prime}=\frac{P_{\text {channel }}}{L}$ is the power per unit length supplied to the microchannel.

The average heat transfer coefficient is calculated as,

$$
h_{a v g}=\frac{q^{\prime \prime}}{\left(T_{f, a v g}-T_{s, a v g}\right)},
$$

where the channel heat flux is given as

$$
q^{\prime \prime}=\frac{P_{\text {channel }}}{A_{s}},
$$

where $\mathrm{A}_{s}$ is the surface area of the heated sides. Note that the total heated surface area is the sum of the area of the bottom and side walls of the microchannel. $T_{f, \text { avg }}$ and $T_{s, \text { avg }}$ are the average fluid and surface temperature, respectively; these are calculated from the corresponding inlet $\left(T_{f, i}\right.$ or $\left.T_{s, i}\right)$ and outlet $\left(T_{f, o}\right.$ or $\left.T_{s, o}\right)$ temperatures as

$$
\begin{aligned}
T_{f, \text { avg }} & =\frac{T_{f, i}+T_{f, o}}{2} \\
T_{s, \text { avg }} & =\frac{T_{s, i}+T_{s, o}}{2} .
\end{aligned}
$$

Then, Nusselt number is calculated as

$$
N u=\frac{h_{\text {avg }} D_{h}}{k},
$$


where $D_{h}$ is the hydraulic diameter ( $=146 \mu \mathrm{m}$ in the present case). The thermal conductivity of working fluid, $k(\mathrm{~W} / \mathrm{m}-\mathrm{K})$ is selected at the inlet fluid temperature. The measured heat transfer coefficient (from Eq. (4)) is compared against the following correlation (by Kosar et al 2005)

$$
h_{t p}=4.068 \times 10^{4}\left(\operatorname{Re}_{l}\right)^{0.12}\left(1-x_{e}\right)^{0.8}\left(\frac{1-x_{e}}{x_{e}}\right)^{0.02}
$$

where $x_{e}$ is the exit quality and $\mathrm{Re}_{l}$ is the Reynolds number corresponding to the total inlet liquid mass flux and liquid viscosity.

\section{Measurement of pressure drop}

Pressure drop study of boiling flow through diverging microchannel with $4^{\circ}$ of divergence angle has been carried out and presented in this section. Experiments have been carried out and 60 data points generated using mass flux range of $118-1182 \mathrm{~kg} / \mathrm{m}^{2}$-s and heat flux range of $1.6-19.2 \mathrm{~W} / \mathrm{cm}^{2}$. The effect of mass flux and heat flux on pressure drop has been studied and explained keeping in view of the different flow regimes observed during the experiments.

\subsection{Effect of mass flux}

Figure 2 shows the variation of pressure drop during flow boiling inside diverging microchannel with mass flux, at three different heat fluxes. The corresponding pressure drop without heating,

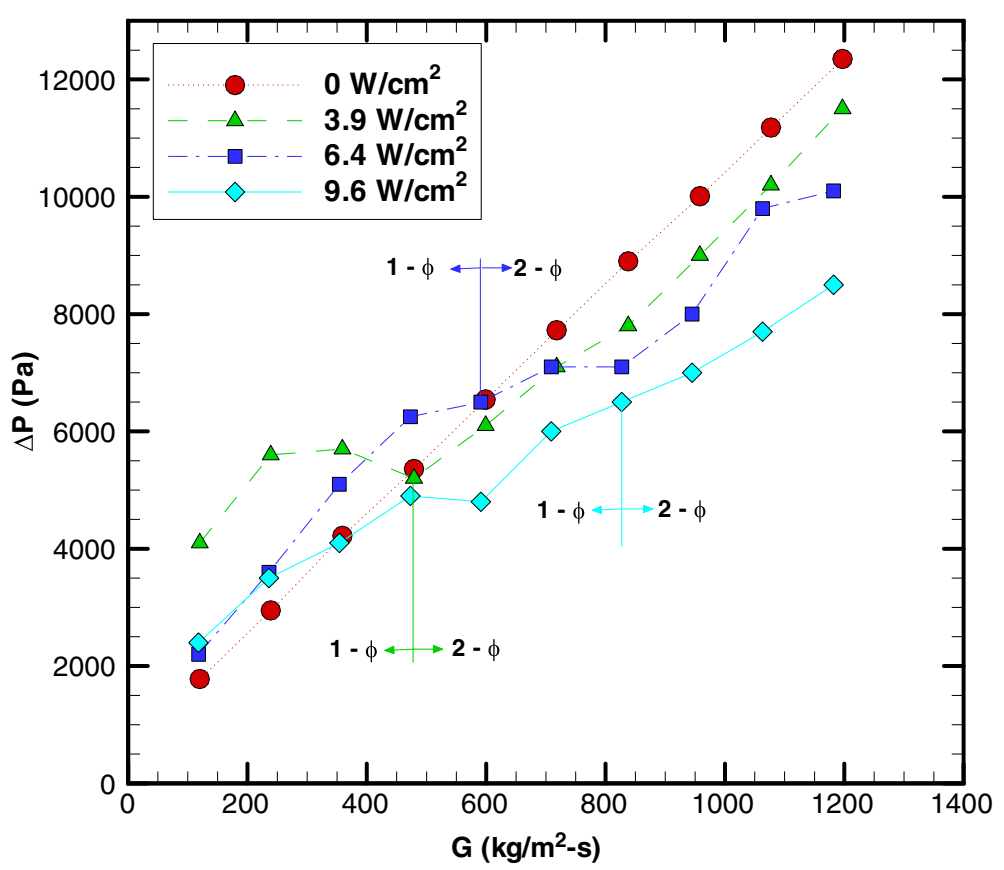

Figure 2. Pressure drop variation with mass flux during flow boiling through a microchannel with divergence angle of $4^{\circ}$. 
which serves as the baseline case, has also been plotted. The baseline pressure drop agrees with that predicted by empirical correlations; as has been shown for other conditions elsewhere (Singh et al 2009c; Bhide et al 2009). Note the linear variation of base line pressure $\left(0 \mathrm{~W} / \mathrm{cm}^{2}\right)$ from the figure. This signifies the dominance of viscous force over inertial force in diverging microchannel (at least for the conditions studied here). More details on this aspect on single-phase flow are presented in our earlier work (Duryodhan et al 2013).

Boiling is observed for all the heated cases in figure 2; the onset of boiling has been marked by a vertical line on each curve. Notice that the pressure drop during single-phase heating is lower than that for no heating case, because of a reduction in viscosity with temperature. Singh et al $2009 \mathrm{c}$ noted that the data at different temperatures collapse onto a single curve upon proper nondimensionalization.) However, the pressure drop increases above the baseline value in presence of boiling. In figure 2, the pressure drop curves for heat flux value of 3.9 and $6.4 \mathrm{~W} / \mathrm{cm}^{2}$ deviate from their respective point of onset of boiling; however, such deviation is not significant for heat flux value of $9.6 \mathrm{~W} / \mathrm{cm}^{2}$. This is because of the rapid growth and departure of bubbles from the site of nucleation for the $9.6 \mathrm{~W} / \mathrm{cm}^{2}$ case. Therefore, unlike uniform cross section microchannel (Singh et al 2009c), the increase in pressure drop at the point of ONB is smaller for diverging microchannel. Such behaviour was also observed in our previous work (Agrawal et al 2012), where it was observed that an increase of the divergence angle results in a decrease in the amount of pressure rise at the ONB.

Figure 2 further shows that the point of onset of boiling point gets shifted towards higher mass flux with an increase in the heat flux. For example, for a heat flux value of $3.9 \mathrm{~W} / \mathrm{cm}^{2}$ boiling initiates at $473 \mathrm{~kg} / \mathrm{m}^{2}$-s, whereas for $6.4 \mathrm{~W} / \mathrm{cm}^{2}$, boiling initiates at $591 \mathrm{~kg} / \mathrm{m}^{2}$-s. This result is along the expected line. Note that the onset of boiling was confirmed through flow visualization.

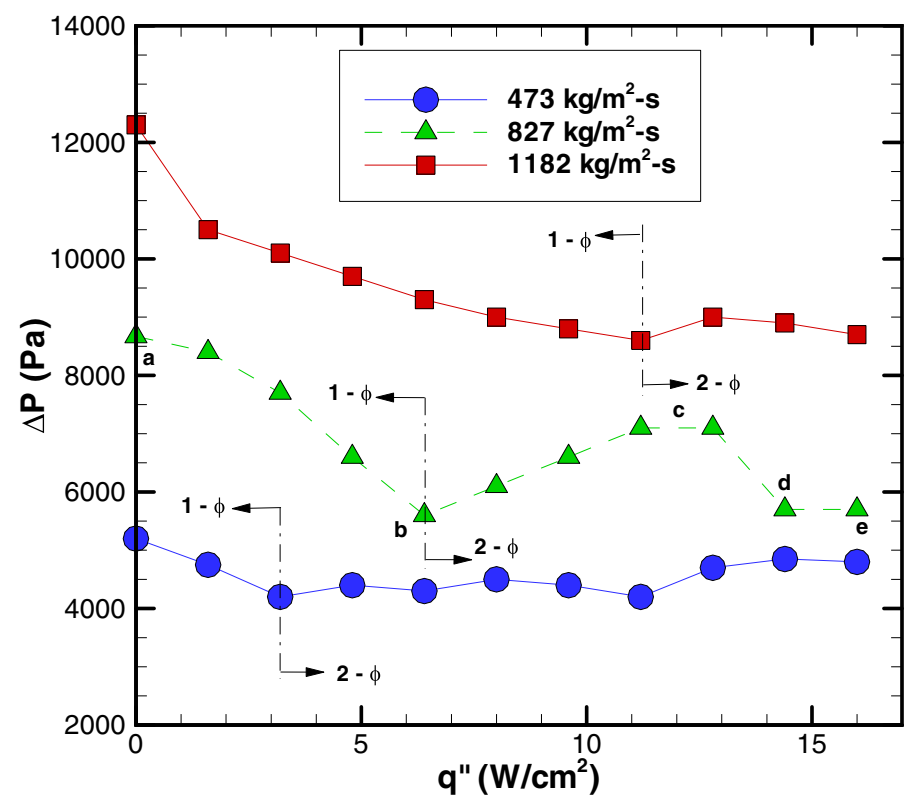

Figure 3. Pressure drop variation with heat flux during flow boiling through a microchannel with divergence angle of $4^{\circ}$. 


\subsection{Effect of heat flux}

Figure 3 shows the effect of heat flux on pressure drop, for three different mass fluxes. The curves in figure 3 can be divided into four parts based on the underlying flow regime, recorded through concurrent flow visualization. In figure 3, the pressure drop curve at mass flux of $827 \mathrm{~kg} / \mathrm{m}^{2}-\mathrm{s}$ is divided into various sub-regimes (marked with ' $a$ ' to ' $\mathrm{e}$ ') observed during the experiment. The pressure drop between ' $a$ ' and ' $b$ ' decreases with heat flux because of single-phase heating, owing to a reduction in viscosity of the fluid. Further increase in heat flux beyond point ' $b$ ' initiates nucleation of bubbles. It is observed that the time period of bubble nucleation to departure is initially small, which results in coalescence of bubbles from nearby nucleation sites. This process results in an increase in the pressure drop between ' $b$ ' and ' $c$ '. The phenomenon happens at a faster rate beyond point ' $c$ '; the flow therefore starts developing larger slugs by coalescence of relatively small moving bubbles. The region between ' $c$ ' and ' $d$ ' therefore shows a decrease in pressure drop with an increase in heat flux. From point ' $d$ ' onwards, the flow progresses towards slug and annular regimes with dry-out regime in between. A further increase in heat flux results in periodic dry-out and rewetting (partial dry-out). The time period of the dry-out regime increases with an increase in heat flux. It is therefore observed that the pressure drop increases beyond point ' $d$ ' with an increase in heat flux, because of the increase of time for which dry-out phase exists. Figure 4 shows the time variation of surface as well as inlet water temperature at inlet. Note that the surface temperature rises above the saturation temperature $\left(T_{\text {sat }}\right)$ during the dry-out regime; whereas it falls below $T_{\text {sat }}$ when there is rewetting. This indicates the presence of partial dry-out regime and its effect on the surface temperature. These four regimes are most prominent at mass flux of $827 \mathrm{~kg} / \mathrm{m}^{2}-\mathrm{s}$; input power is not sufficient at higher mass flux of $1182 \mathrm{~kg} / \mathrm{m}^{2}-\mathrm{s}$ to elucidate all the four regimes. Wherever, at lower mass flux of $473 \mathrm{~kg} / \mathrm{m}^{2}$-s the pressure drop does not vary much across the regimes due to the relatively small contribution of frictional

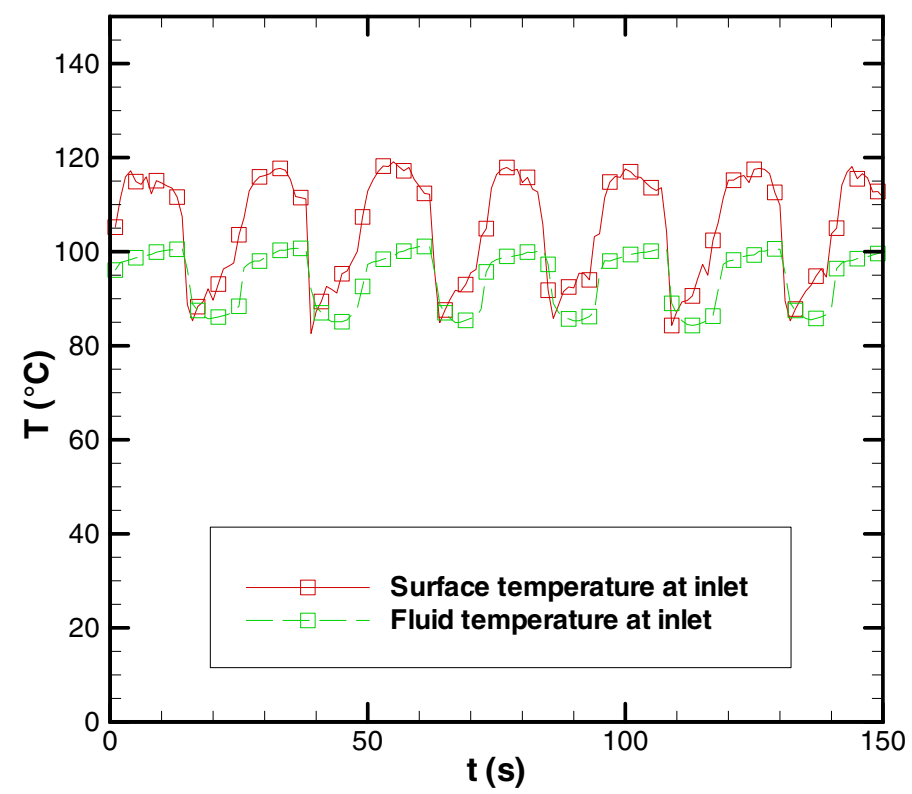

Figure 4. Surface and bulk fluid temperature variation with time indicating presence of partial dry-out regime. 
pressure drop. Evidence for all these flow regimes in a uniform cross section microchannel has been presented in Singh et al (2009c).

\section{Heat transfer coefficient and Nusselt number}

Thermodynamic quality at outlet of microchannel has been calculated at different heat fluxes using Eq. (3) and plotted in figure 5, for the three mass fluxes. The figure shows that the flow attains saturated liquid condition at a higher heat flux, with an increase in the mass flux. For example, at mass flux of $473 \mathrm{~kg} / \mathrm{m}^{2}-\mathrm{K}$ the flow attains saturated liquid condition at heat flux value of $4.8 \mathrm{~W} / \mathrm{cm}^{2}$, whereas for $1182 \mathrm{~kg} / \mathrm{m}^{2}-\mathrm{K}$ this condition is attained at $12.8 \mathrm{~W} / \mathrm{cm}^{2}$. This is consistent with the pressure drop graph shown in figure 3 where the point of flow transition from single-phase to two-phase indicates the saturated liquid condition.

Figure 6 shows the variation of average heat transfer coefficient $\left(h_{a v g}\right)$ with supplied heat flux at three different mass fluxes. For higher mass flux value of $1182 \mathrm{~kg} / \mathrm{m}^{2}-\mathrm{s}$, the flow mostly remains in the single-phase regime. This can be explained by the variation of exit thermodynamic quality plotted in figure 5. Therefore at this mass flux, the variation of heat transfer coefficient remains close to the theoretical value obtained using the correlation of Kosar et al (2005). Note that the experimental values are lower than that obtained from the correlation of Kosar et al at lower heat flux; whereas the experimental values are higher at higher heat flux. For a lower mass flux, $h_{a v g}$ increases with an increase in the heat flux. The variation of $h_{\text {avg }}$ deviates from the corresponding theoretical value with decreasing mass flux from 1182 to $473 \mathrm{~kg} / \mathrm{m}^{2}$-s and may even exhibit a maxima at higher heat flux. For example, for mass flux $473 \mathrm{~kg} / \mathrm{m}^{2}$-s, figure 6a shows maximum value of $h_{\text {avg }}$ at heat flux $11.3 \mathrm{~W} / \mathrm{cm}^{2}$. The maxima occurs during the bubbly-slug boiling regime. Whereas, drop in $h_{\text {avg }}$ has been observed during alternate dry-out and rewetting phenomenon that occurs at

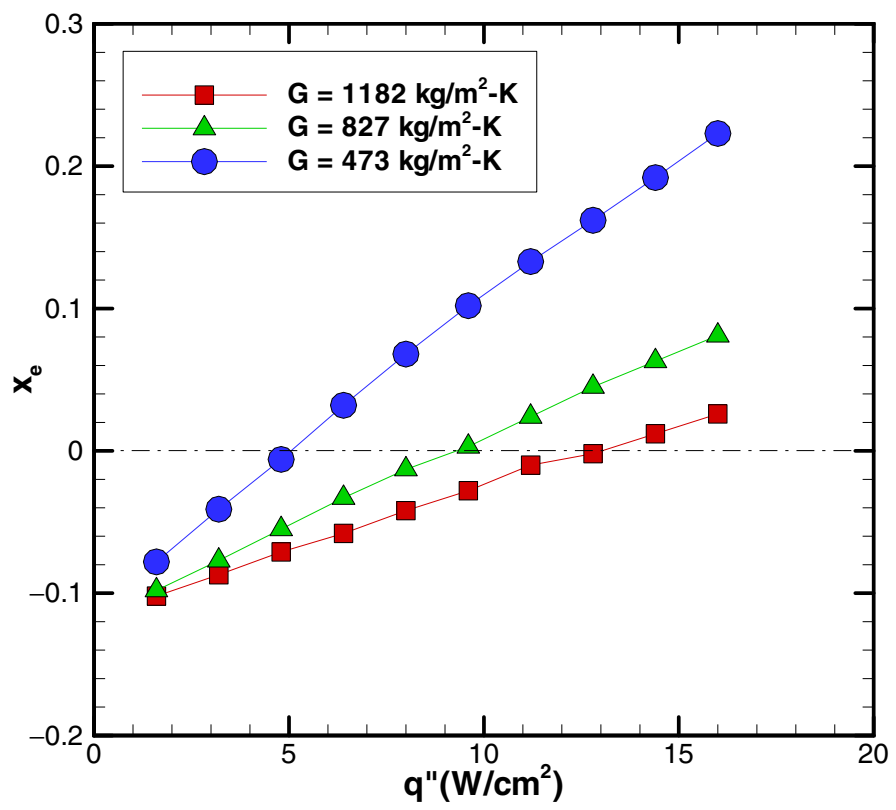

Figure 5. Variation of exit thermodynamic quality with heat flux, for three different mass fluxes. 


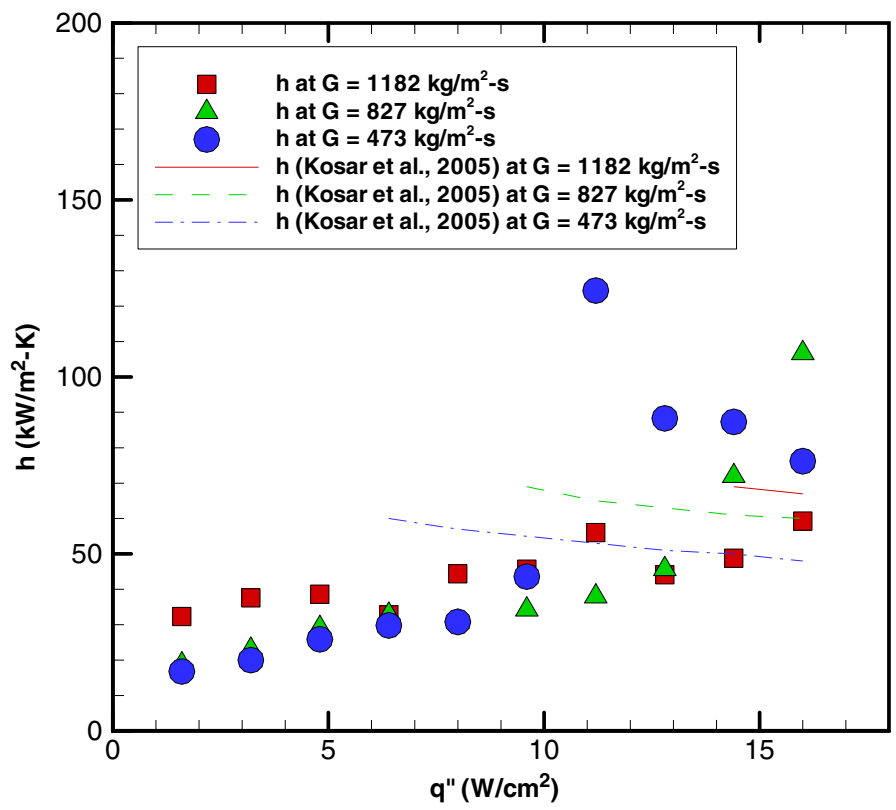

(a)

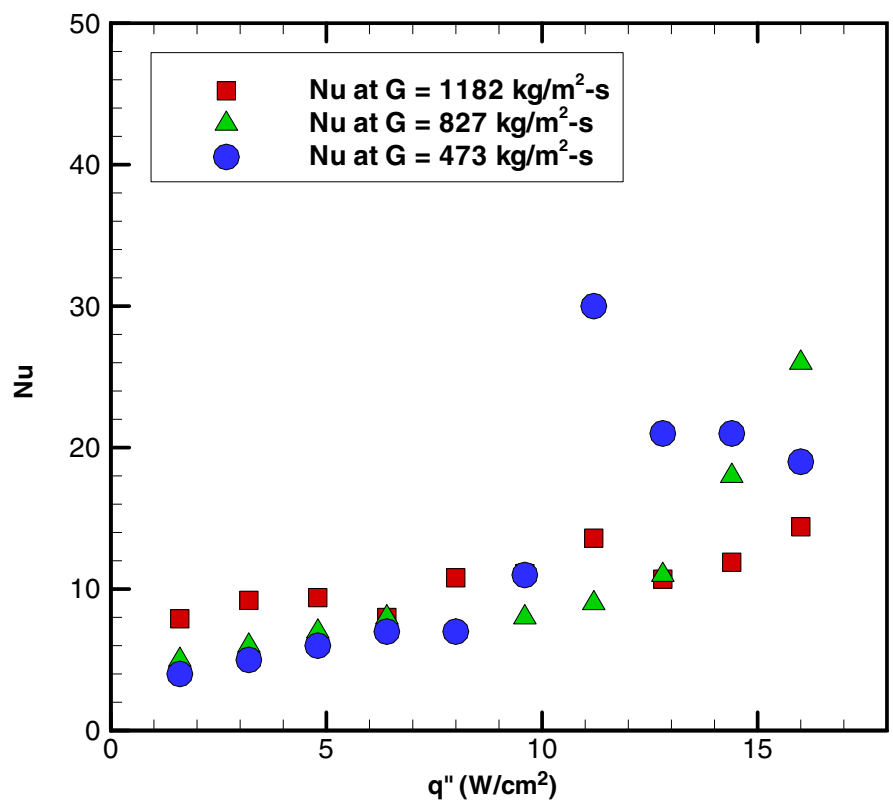

(b)

Figure 6. Variation of heat transfer coefficient and Nusselt number with heat flux. Comparison with empirical correlation of Kosar et al (2005), where exit quality is greater than zero, is also included in (a).

higher heat flux. No backflow is however observed during dry-out, which happens periodically for very short time duration. The corresponding variation of Nusselt number $(\mathrm{Nu})$ with heat flux is plotted in figure 6b. It is observed that for mass flux of $1182 \mathrm{~kg} / \mathrm{m}^{2}-\mathrm{s}$, 


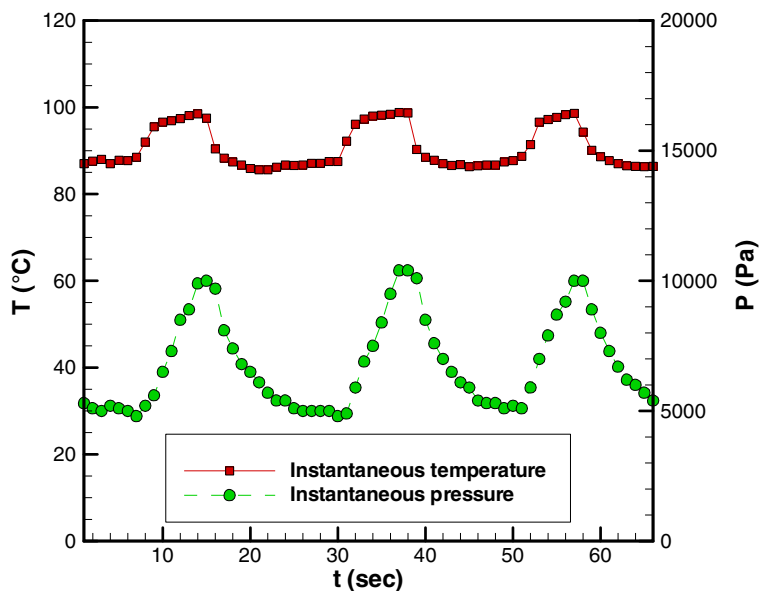

(a)

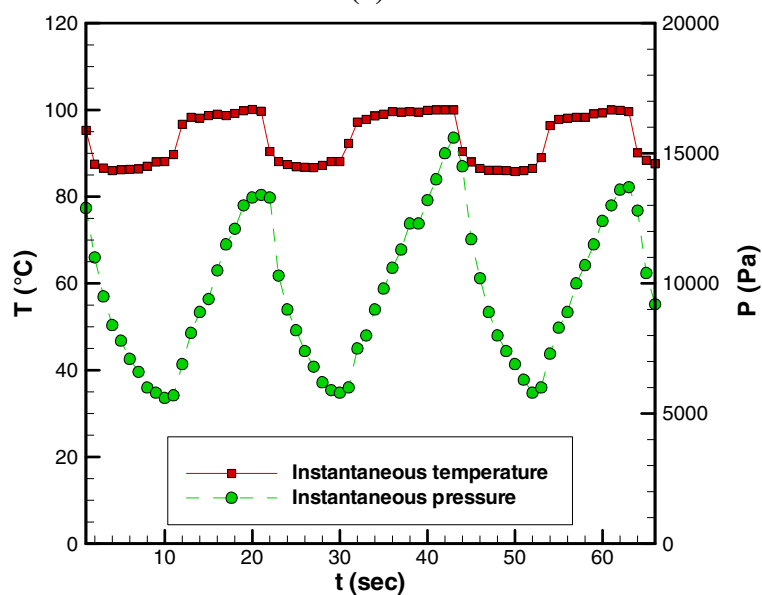

(b)

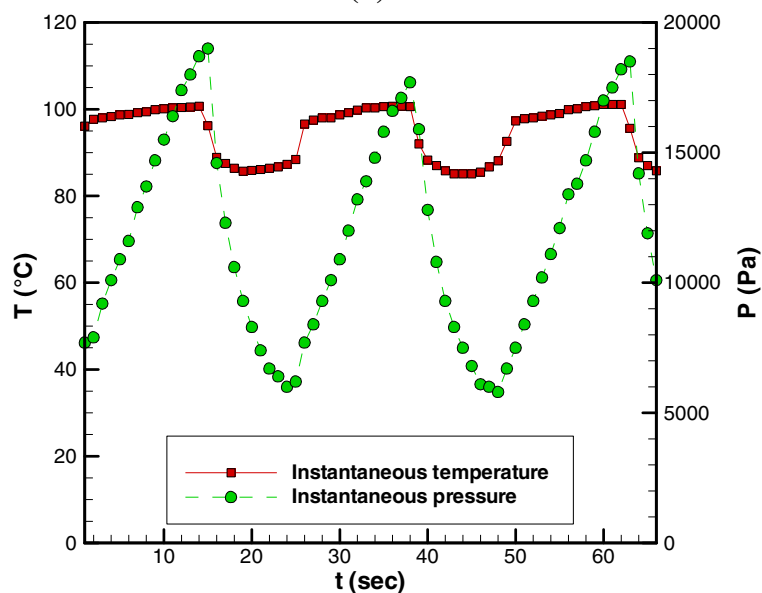

(c)

Figure 7. Transient temperature and pressure variations, with $G=827 \mathrm{~kg} / \mathrm{m}^{2}$-s and heat flux of (a) $16.0 \mathrm{~W} / \mathrm{cm}^{2}$, (b) $17.6 \mathrm{~W} / \mathrm{cm}^{2}$, and (c) $19.2 \mathrm{~W} / \mathrm{cm}^{2}$. 
the average value of $\mathrm{Nu}$ is about 15 , which reaches to 46 for lower mass flux of $473 \mathrm{~kg} / \mathrm{m}^{2}$-s. But for the other two mass fluxes ( 827 and $473 \mathrm{~kg} / \mathrm{m}^{2}-\mathrm{s}$ ), Nu increases with an increase in heat flux, as evident from figure $6 b$.

\section{Pressure and temperature instabilities}

Effect of heat flux on heat transfer coefficient for boiling flow through diverging microchannel has been studied in the previous section. The result shows that the heat transfer coefficient increases significantly before the onset of dry-out which happens beyond $19.2 \mathrm{~W} / \mathrm{cm}^{2}$ (not shown

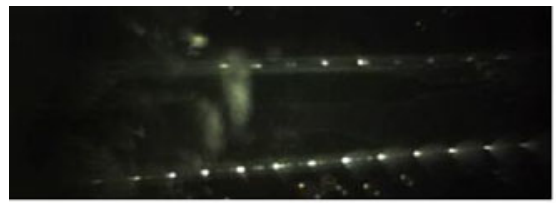

$7 \mathrm{sec}, \mathrm{P}=48 \mathrm{mbar}, \mathrm{T}=88.5^{\circ} \mathrm{C}$.

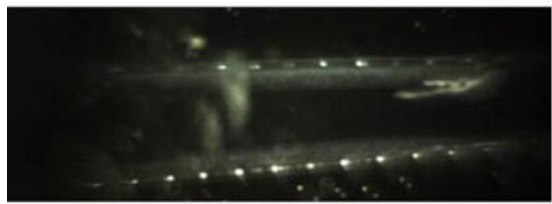

$11 \mathrm{sec}, \mathrm{P}=73 \mathrm{mbar}, \mathrm{T}=96.9^{\circ} \mathrm{C}$.

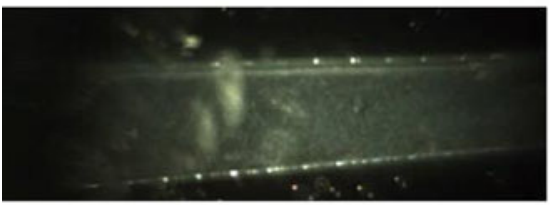

15 sec, $\mathrm{P}=100 \mathrm{mbar}, \mathrm{T}=97.5^{\circ} \mathrm{C}$.

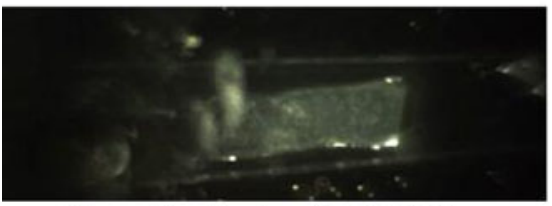

22 sec, $\mathrm{P}=57$ mbar, $\mathrm{T}=85.6{ }^{\circ} \mathrm{C}$.

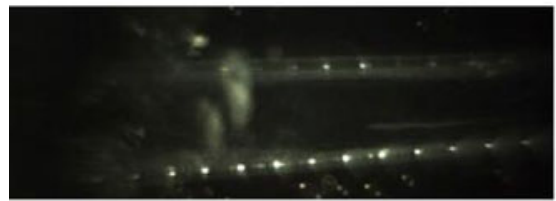

30 sec, $\mathrm{P}=48$ mbar, $\mathrm{T}=87.5^{\circ} \mathrm{C}$.

(a) $16.0 \mathrm{~W} / \mathrm{cm}^{2}$

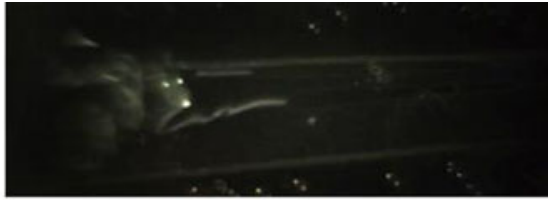

$10 \mathrm{sec}, \mathrm{P}=56 \mathrm{mbar}, \mathrm{T}=88.1^{\circ} \mathrm{C}$.

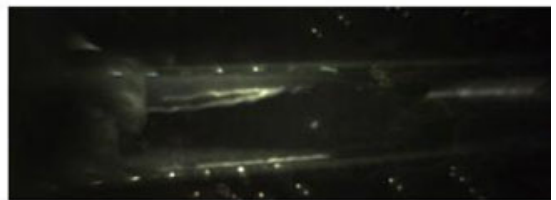

$15 \mathrm{sec}, \mathrm{P}=99.5 \mathrm{mbar}, \mathrm{T}=99.5^{\circ} \mathrm{C}$.

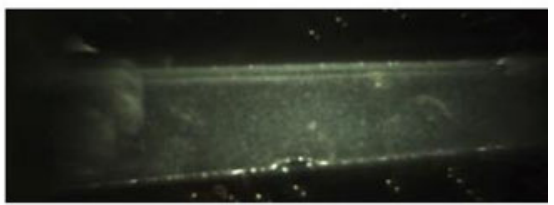

$21 \mathrm{sec}, \mathrm{P}=134$ mbar, $\mathrm{T}=99.7^{\circ} \mathrm{C}$.

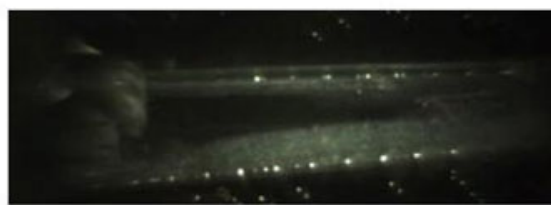

25 sec, $\mathrm{P}=78 \mathrm{mbar}, \mathrm{T}=86.8^{\circ} \mathrm{C}$.

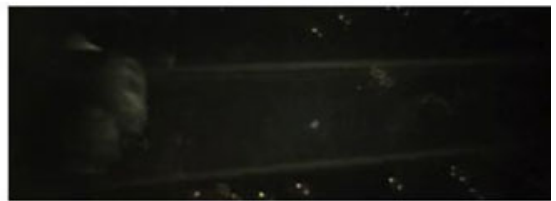

$30 \mathrm{sec}, \mathrm{P}=58 \mathrm{mbar}, \mathrm{T}=88.1{ }^{\circ} \mathrm{C}$.

(b) $17.6 \mathrm{~W} / \mathrm{cm}^{2}$

Figure 8. Different flow regimes for one cycle of pressure rise, corresponding to the case presented in figures $7 \mathrm{a}$ and $\mathrm{b}$. 
in figure 6a) for mass flux of $827 \mathrm{~kg} / \mathrm{m}^{2}$-s. Therefore, in order to check the viability of employing the flow in this high heat transfer coefficient regime, the instability study of pressure and inlet temperature has been carried out in this section.

Figure 7 shows the transient variation of pressure and temperature with mass flux of $827 \mathrm{~kg} / \mathrm{m}^{2}$-s at three different heat fluxes $\left(16.0,17.6\right.$ and $\left.19.2 \mathrm{~W} / \mathrm{cm}^{2}\right)$. Comparison of figures $7 \mathrm{a}-\mathrm{c}$ show that the amplitude of pressure fluctuation increases with an increase in heat flux. The standard deviation of pressure varies as 1763, 2814 and $3954 \mathrm{~Pa}$ respectively for heat flux values of 16.0, 17.6 and $19.2 \mathrm{~W} / \mathrm{cm}^{2}$, at constant mass flux of $827 \mathrm{~kg} / \mathrm{m}^{2}-\mathrm{s}$. Lu and Pan (2009) defined flow with pressure fluctuation of $3000 \mathrm{~Pa}$ to be unstable in a diverging microchannel (full divergence angle of $1^{\circ}$ ); they observed back flow in inlet reservoir for such cases. In the present study, even at the pressure fluctuation of $3954 \mathrm{~Pa}$, no back flow into the inlet reservoir was noticed. Also, as evident from figure 7 , we did not observe any substantial change in fluctuation of the inlet temperature.

However, the frequency of phase change (from dry-out to single-phase) increases with an increase in heat flux. This is collaborated through flow visualization presented through figure 8 . The figure shows that the time required to change dry-out regime to single-phase regime is around $15 \mathrm{~s}$; the change is smooth from a mixture of annular/slug flow regime to dry-out (see figure 8a). Whereas, figure $8 \mathrm{~b}$ shows that this change in phase occurs in $9 \mathrm{~s}$ at the higher heat flux. Also, the residence period for which temperature lies below the average value decreases with an increase in heat flux from 16.0 to $19.2 \mathrm{~W} / \mathrm{cm}^{2}$.

It is observed that more slug-annular mixture is present in case of flow with supplied heat flux of $16.0 \mathrm{~W} / \mathrm{cm}^{2}$, whereas more dry-out is present in case of flow with supplied heat flux of 17.6 and $19.2 \mathrm{~W} / \mathrm{cm}^{2}$. Therefore, significant heat transfer coefficient (up to $107 \mathrm{~kW} / \mathrm{m}^{2}-\mathrm{K}$ ) can be achieved with controlled supplied heat flux of $16.0 \mathrm{~W} / \mathrm{cm}^{2}$ at the cost of lower pressure drop, as seen earlier in figure 3 for mass flux of $827 \mathrm{~kg} / \mathrm{m}^{2}-\mathrm{s}$.

\section{Conclusions}

We have experimentally investigated the effect of heat flux and mass flux on pressure drop and heat transfer coefficient with boiling in diverging microchannel. Concurrently, the corresponding flow regimes are recorded. It is observed that the increase in pressure drop at the onset of boiling is smaller for diverging microchannel as compared to a uniform cross section microchannel. Four flow regimes i.e., bubbly, slug, slug-annular and periodic dry-out/ rewetting have been observed during boiling experiment. Effect of heat flux on pressure drop shows maxima during transition from bubbly to slug regimes. Frequency of dry-out regime is observed to be small for the heat flux range used in the present study. The average heat transfer coefficient is observed to be maximum during slug-annular regime for relatively small pressure drop penalty and with good flow stability. The transient pressure and temperature variations during periodic dry-out/ rewetting show that the frequency of dry-out increases with an increase in heat flux and result in more flow instabilities. These results provide insights into boiling in diverging microchannels.

\section{References}

Agrawal A and Singh S G 2011 A review of state-of-the-art on flow boiling of water in microchannel. Int. J. Microscale and Nanoscale Thermal and Fluid Transport Phenomena 2: 1-39

Agrawal A, Duryodhan V S and Singh S G 2012 Pressure drop measurements with boiling in diverging microchannel. Frontiers in Heat and Mass Transfer 3: 1-7 
Bergles A E and Kandlikar S G 2005 On the nature of critical heat flux in microchannels. J. Heat Transfer 127(10): 101-107

Bhide R R, Singh S G, Sridharan A, Duttagupta S P and Agrawal A 2009 Pressure drop and heat transfer characteristics of boiling water in sub-hundred micron channel. Experimental Thermal and Fluid Science 33: 963-975

Bhide R R, Singh S G, Sridharan A and Agrawal A 2011 An active control strategy for reduction of pressure instabilities during flow boiling microchannel. J. Micromechanics and Microengineering 21: 035021

Duryodhan V S, Singh S G and Agrawal A 2013 Liquid flow through a diverging microchannel. Microfluidics and Nanofludics 14(1-2): 53-67

Kandlikar S G 2002 Fundamental issues related to flow boiling in minichannels and microchannels. Experimental Thermal and Fluid Science 26: 389-407

Kandlikar S G 2006 Nucleation characteristic and stability considerations during flow boiling in microchannels. Experimental Thermal and Fluid Science 30: 441-447

Kandlikar S G and Balasubramanian P 2005 Effect of gravitational orientation on flow boiling of water in 1054 - 197 micron parallel minichannels. ASME Paper No. ICMM 2004-2379, In: Second International Conference on Microchannels and Minichannels, Rochester, NY, USA, 17-19 June 2004, J. Heat Transfer 127, pp. 539-550

Kennedy J E, Roach G M, Dowling M F, Abdel-Khalik S I, Ghiaasiaan S M and Jeter S M 2000 The onset of flow instability in uniformly heated horizontal microchannels. J. Heat Transfer 122: $118-125$

Kosar A, Kuo C and Peles Y 2005 Boiling heat transfer in rectangular microchannels with reentrant cavities. International Journal of Heat and Mass Transfer 48: 4867-4886

Kuo C J and Peles Y 2008 Flow boiling instabilities in microchannels and means for mitigation by reentrant cavities. J. Heat Transfer ASME 1301-1310

Lee P C and Pan C 2008 Boiling heat transfer and two-phase flow of water in a single shallow microchannel with a uniform or diverging cross section. J. Micromechanics and Microengineering 13: 18

Lee P C, Tseng F G and Pan C 2004 Bubble dynamics in microchannels: Part I. Single microchannel. International Journal of Heat and Mass Transfer 47: 5575-5589

Li H Y, Tseng F G and Pan C 2004 Bubble dynamics in microchannels: Part II. Two parallel microchannels. International Journal of Heat and Mass Transfer 47: 5591-5601

Lu C T and Pan C 2009 A highly stable microchannel heat sink for convective boiling. J. Micromechanics and Microengineering 19: 13

Mudawar I 2001 Assessment of high-heat-flux thermal management schemes. IEEE Transactions on Component and Packaging Technologies 24: 122-141

Park J E, Thome J R and Michel B 2009 Effect of inlet orifice on saturated CHF and flow visualization in multi-microchannel heat sinks. 25th IEEE SEMI-THERM Symposium

Qu W and Mudawar I 2003 Measurement and prediction of pressure drop in two-phase micro-channel heat sinks. International Journal of Heat and Mass Transfer 46: 2737-2753

Qu W and Mudawar I 2004 Measurement and correlation of critical heat flux in two-phase micro-channel heat sinks. International Journal of Heat and Mass Transfer 47: 2045-2059

Singh S G, Kulkarni A, Duttagupta S P, Puranik B P and Agrawal A 2008 Impact of aspect ratio on flow boiling of water in rectangular microchannels. Experimental Thermal and Fluid Science 33: $153-160$

Singh S G, Duttagupta S P and Agrawal A 2009a In-situ impact analysis of very high heat flux transients on non-linear $\mathrm{p}-\mathrm{n}$ diode characteristics and mitigation using on-chip single-phase and two-phase microfluidics. J. Microelectromechanical Systems 18(6): 1208-1219

Singh S G, Jain A, Sridharan A, Duttagupta S P and Agrawal A 2009b Flow map and measurement of void fraction and heat transfer coefficient using image analysis technique for flow boiling of water in silicon microchannel. J. Micromechanics and Microengineering 19, 075004: 1-9

Singh S G, Bhide R R, Duttagupta S P, Puranik B P and Agrawal A 2009c Two-phase flow pressure drop characteristics in trapezoidal silicon microchannels. IEEE Transactions on Components and Packaging Technologies 32(4): 887-900 
Singh S G, Agrawal A and Duttagupta S P 2011 Reliable MOSFET operation using two-phase microfluidics in presence of high heat flux transients. J. Micromechanics and Microengineering 21: 105002

Wang G, Cheng P and Bergles A E 2008 Effects of inlet/outlet configurations on flow boiling instability in parallel microchannels. International Journal of Heat and Mass Transfer 51: 2267-2281

Wu H Y and Cheng 2006 Pressure drop and flow boiling instabilities in silicon microchannel heat sinks. J. Micromechanics and Microengineering 16: 2138-2146 